\title{
Analysis of small intermediate relays from leading manufacturers
}

\author{
Yu.M. Zaytsev ${ }^{1}$, A.V. Mikhailov ${ }^{1}$, E.V. Mikhailova ${ }^{2}$, N.N. Nikolaev ${ }^{1}$, V.N. Petrov ${ }^{1, *}$, and D.S. Sazanov ${ }^{1}$ \\ ${ }^{1}$ Chuvash State University named after I.N. Ulyanov, 428015, Cheboksary, Chuvash Republic, Russia, Moskovsky pr. 15 \\ ${ }^{2}$ Kazan State Power Engineering University, 420066 Kazan, Republic of Tatarstan, Russia, Krasnoselskaya 51
}

\begin{abstract}
This paper presents a comparative analysis of technical characteristics and designs of small intermediate relays from various manufacturers. The following main characteristics of relay are considered: operation and release values; weight and dimensions; power consumption; time parameters; reliability characteristics. The design of the relays of the Russian and international manufacturers are being discussed, their design features that affect the technical characteristics are considered. It is noted that the fastening of movable contacts directly to the armature (relays from Finder, Relpol, Irkutsk Relay Plant) requires a flexible connection with the relay contacts, which leads to more complicated assembly and calibration of relays. It is shown that the kinematic diagram in the presence of free travel with no mechanical coupling with the contact pusher, used in the relay from Schrack, can reduce power consumption and increase the vibration and shock resistance of the relay break contacts. In Schrack AC relays, the operating clearance zone is configured to create a short-circuited loop with reduced electrical resistance and to provide optimum conditions for reducing armature vibration. The appropriate relay designs in terms of improving technical characteristics are proposed. The advantage of a flat return spring over cylindrical coil springs in terms of manufacturing technology and stability of mechanical characteristics of relay is shown. It was revealed that the electromagnetic drive of the Schrack relay compares favorably with electromagnetic drives of other companies in terms of the use of stray magnetic fluxes to create a useful electromagnetic torque. Based on the results of the comparative analysis and experimental study of existing relay designs, recommendations were formulated for the development of a new series of the Russian small intermediate relays within the framework of the import substitution program.
\end{abstract}

\section{Introduction}

Small intermediate relays (SIR) are widely used in relay protection and automation (RPA) cabinets of power facilities. Their functions are to control relatively powerful loads with relatively low switching durability, provide galvanic isolation between input and output circuits, and increase noise immunity. On average, 6-10 or even more relays can be installed in RPA cabinets.

The Russian electrical and energy enterprises in their products most widely use imported relays from Finder (Italy), Schrack (Austria), Relpol (Poland) as there is no competitive SIR produced in Russia. So, within the framework of the import substitution program, there is a need to develop and introduce into production a new series of SIR possessing characteristics at the level of the best international samples.

\section{Methods}

This work is a continuation of work [1]. It presents a deeper analysis of relays produced by various manufacturers in order to develop recommendations for design solutions when developing and implementation of the Russian SIR of a new series [2-24]. The relays of companies Finder, Relpol, Schrack, Irkutsk Relay Plant [2-9] are considered as analogs of the developed SIR, as they most fully meet the requirements of customers.

Tables 1 and 2 show the main technical characteristics of relays manufactured in various countries.

\section{Results}

The performed comparative analysis of technical parameters shows that the Russian relays are significantly worse than that produced in other countries in terms of weight, size, power consumption, aesthetic indicators, presence of individual sockets, etc. A specific requirement for SIR usage in terminals is the response voltage in the range $0.6 \div 0.65$ of rated supply voltage [10]. Currently, the Russian SIRs do not fully meet all modern requirements that are set by the developers of relay protection. Even their modernization does not result in a drastic improvement of technical characteristics. Some exceptions concern the RP-Ir2 relay from the Irkutsk Relay Plant, which was put into

* Corresponding author: pvn.chuvsu@yandex.ru 
Table 1. The main technical characteristics of relays manufactured in various countries (not in Russia).

\begin{tabular}{|c|c|c|c|c|}
\hline \multicolumn{2}{|c|}{ Characteristics } & $\begin{array}{c}\text { Finder } \\
55.3 \text { series }\end{array}$ & $\begin{array}{c}\text { Relpol } \\
\text { R4N series }\end{array}$ & Schrak PT570000 series \\
\hline \multicolumn{2}{|l|}{ Design } & \multicolumn{3}{|c|}{4 switching contacts } \\
\hline \multicolumn{2}{|c|}{$\begin{array}{l}\text { Rated switching voltage, } \\
\text { V }\end{array}$} & $250(\mathrm{AC})$ & $250(\mathrm{AC})$ & $240(\mathrm{AC})$ \\
\hline \multicolumn{2}{|c|}{ Rated contact current, $\mathrm{A}$} & 7 & 7 & 6 \\
\hline \multirow{2}{*}{$\begin{array}{l}\text { Rated coil } \\
\text { voltage, } \mathrm{V}\end{array}$} & DC & \multicolumn{2}{|c|}{$6 ; 12 ; 24 ; 48 ; 60 ; 80 ; 110 ; 125 ; 220$} & $6 \ldots 220$ \\
\hline & $\mathrm{AC}$ & \multicolumn{2}{|c|}{$\begin{array}{c}6 ; 12 ; 24 ; 48 ; 60 ; 80 ; \\
110 ; 120 ; 220 ; 230 ; 240\end{array}$} & $6 \ldots 230$ \\
\hline \multicolumn{2}{|c|}{ Response time, ms } & 11 & 13 & 15 \\
\hline \multicolumn{2}{|c|}{ Consumed power, W/VA } & $1.0 / 1.5$ & $0.9 / 1.6$ & $0.75 / 1.0$ \\
\hline \multicolumn{2}{|c|}{ Electrical life } & $150 \times 10^{3}$ & $100 \times 10^{3}$ & $100 \times 10^{3}$ \\
\hline \multicolumn{2}{|c|}{ Dimensions, mm } & $27.7 \times 37.2 \times 20.7$ & $27.4 \times 35.5 \times 21$ & $28 \times 29 \times 22.5$ \\
\hline
\end{tabular}

Table 2. The main technical characteristics of relays manufactured in Russia.

\begin{tabular}{|c|c|c|c|c|c|}
\hline \multicolumn{2}{|l|}{ Characteristics } & RP21MN-004 & REP26-004 & REK59 & RP-Ir2 \\
\hline \multicolumn{2}{|l|}{ Design } & \multicolumn{4}{|c|}{4 switching contacts } \\
\hline \multicolumn{2}{|c|}{ Rated switching voltage, $\mathrm{V}$} & $380(\mathrm{AC})$ & $380(\mathrm{AC})$ & $380(\mathrm{AC})$ & $220(\mathrm{AC})$ \\
\hline \multicolumn{2}{|c|}{ Rated contact current, A } & 6 & 6 & 6 & 7 \\
\hline \multirow{2}{*}{$\begin{array}{l}\text { Rated coil } \\
\text { voltage, } \mathrm{V}\end{array}$} & DC & \multicolumn{3}{|c|}{$6 ; 12 ; 15 ; 24 ; 48 ; 60 ; 110 ; 220$} & $\begin{array}{c}6 ; 12 ; 24 ; 48 ; 60 ; \\
110\end{array}$ \\
\hline & $\mathrm{AC}$ & \multicolumn{3}{|c|}{$12 ; 24 ; 40 ; 110 ; 220 ; 240 ; 380$} & - \\
\hline \multicolumn{2}{|c|}{ Response time, $\mathrm{ms}$} & 30 & 30 & 40 & 20 \\
\hline \multicolumn{2}{|c|}{ Consumed power, W/VA } & $2.5 / 3.5$ & $2.5 / 3.0$ & $1.6 / 2.8$ & $1.4 /-$ \\
\hline \multirow{2}{*}{\multicolumn{2}{|c|}{ Electrical life }} & $100 \times 10^{3}$ & $100 \times 10^{3}$ & $50 \times 10^{3}$ & $100 \times 10^{3}$ \\
\hline & Dimensions, $\mathrm{mm}$ & $34 \times 45 \times 34$ & $34 \times 48 \times 34$ & $36 \times 48 \times 42$ & $28 \times 37.2 \times 20.7$ \\
\hline
\end{tabular}

production at the beginning of the 21 st century. However, the product does not meet the requirements of consumers as it has low speed, and no options for rated voltage of $220 \mathrm{~V} \mathrm{DC}$ and $230 \mathrm{~V}$ AC of $50 / 60 \mathrm{~Hz}$. At the same time, relays for rated voltages of $220 \mathrm{~V}$ DC and $230 \mathrm{~V} \mathrm{AC}$ of $50 / 60 \mathrm{~Hz}$ make up a significant share in relay protection, telemechanics and automation devices. The combination of the above listed disadvantages limits the area of possible import substitution by the RP-Ir2 product.

\section{Discussion}

General view of the 55.34.9.220.9202 series relay of 220 V DC from Finder (Italy) is shown in Figure 1.

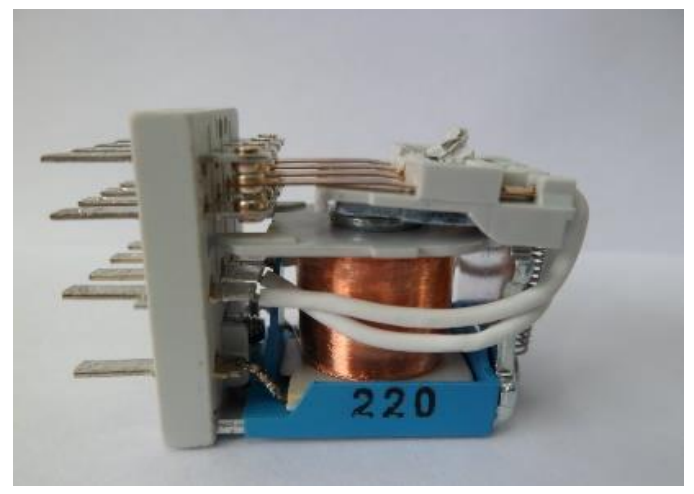

Fig. 1. The 55.34.9.220.9202 series relay of $220 \mathrm{~V}$ DC from Finder (Italy).

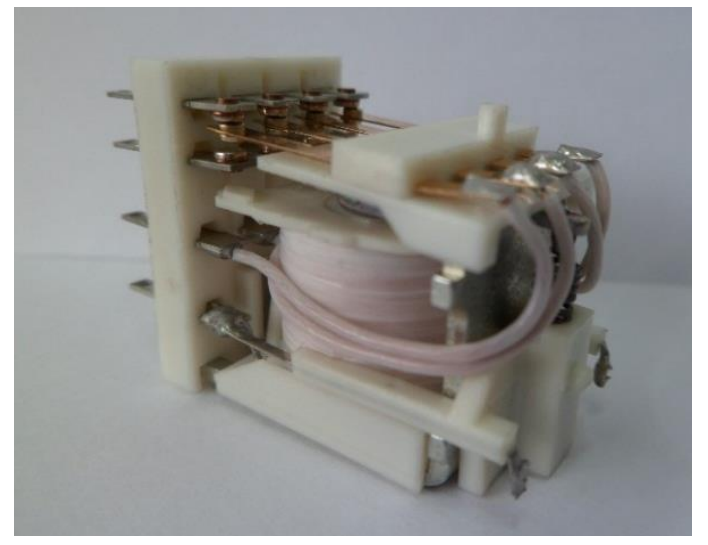

Fig. 2. The RP-Ir2 1.4.P.0.0.D.119.0.06.1 series relay of $110 \mathrm{~V}$ constant voltage from Irkutsk Relay Plant (Russia).

The relay consists of a base with mounted fixed terminals of a contact system with four switching contacts and an electromagnet screwed into a U-shaped bracket (heelpiece). The axis of the electromagnet core is parallel to the base plane.

A distinctive feature of this relay is the arrangement of movable terminals in a plastic block rigidly fixed to the armature (Figure 1). This arrangement provides for the presence of four connecting conductors located in the relay housing.

The electromagnet of the valve-type relay is with an L-shaped bracket (yoke) and a cylindrical core with a round pole piece. A cylindrical plastic frame is installed on the core, on which the winding is wound. The core is riveted to the U-shaped bracket. The winding pins are soldered to the corresponding pins. The return spring of 
the electromagnet is twisted cylindrical, works in tension.

The design and operation principle of the Relpol R4N series relay (Poland) is practically similar to that of the relay from Finder (Italy).

The general view of the RP-Ir2 1.4.P.0.0.D.119.0.06.1 series relay of $110 \mathrm{~V} \mathrm{DC}$ voltage from Irkutsk Relay Plant is shown in Figure 2 (the electronic unit in a form of printed circuit board is not shown).

The winding leads are soldered to the plates embedded in the plastic block, which in turn are soldered to the external winding connections on one side and to the printed circuit board of the electronic unit on the other side.

The rest relay design is similar to the Finder relay described above.

The electromagnetic drive used in the abovementioned relays is structurally a classic valve-type magnetic system. The component arrangement of the considered Russian and international products is almost identical. At present, such a classical magnetic system has practically reached the maximum possible technical parameters of the relay: switching, power consumption, speed and the smallest possible size. The RP-Ir2 product resembles the Finder series 55.3 relay in design (kinematic diagram, magnetic system configuration, counter characteristic), except for some minor details that do not affect the operation. However, it is not possible to achieve identical technical parameters (speed, power consumption) and there are no versions for $=220$ $\mathrm{V}$ and $\sim 230 \mathrm{~V}$, for $50 / 60 \mathrm{~Hz}$. Due to the high level of production and automation at enterprises, the relay from Finder has better technical characteristics in comparison with the product from the Irkutsk Relay Plant.

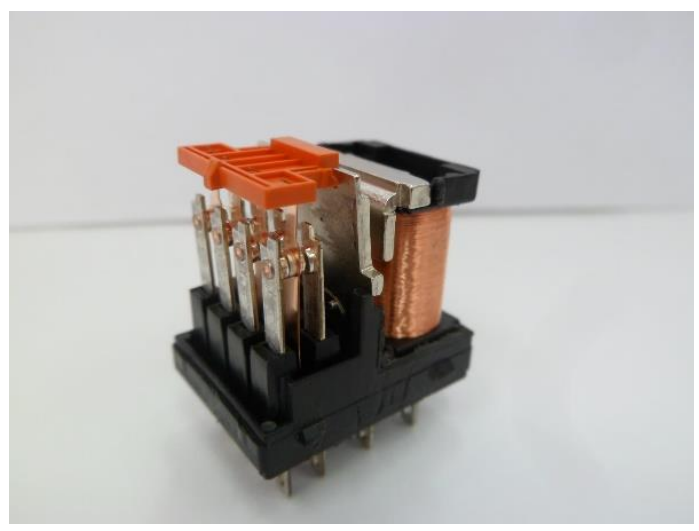

Fig. 3. BC $220 \mathrm{~V}$ voltage intermediate relay.

Figure 3 presents the Schrack PT570220 series relay $[4,11]$. The relay consists of a contact system with four switching contacts mounted on a single plastic base. The criteria for assessing the technical state of contact groups are considered in [12-16]. An electromagnetic system is also installed there. Forces from the electromagnet armature to the moving contacts are transferred by a plastic pusher. External connections (pins) of fixed and movable terminals are brought out to the rear of the base. Fixed terminals and their external connections (pins) form a single whole and are located in the same plane.
Movable terminals and their external connections are located in different planes, offset from each other. The movable terminals are connected with pins using special conductors mounted inside the base, which eliminates the need to connect contacts and pins with separate conductors located in the relay housing. This design greatly simplifies the relay assembly.

The magnetic system of electromagnet consists of the following parts: an L-shaped armature, a L-shaped core and a coil with a plastic frame, extended along the depth of the relay. Such an electromagnet system allows using stray magnetic fluxes to create a useful electromagnetic torque for the force action in the working gap (Figure 4), reaching $10-15 \%$ of the total torque.

In a relay with constant voltage control, the core of the magnetic system has a developed pole area due to the corresponding bend (Figure 3). The axial working clearance is $1.2 \mathrm{~mm}$. The return spring is made in the form of a flat plate close to the L-shaped one, one end of which is fixed on the electromagnet core, the other on the armature.

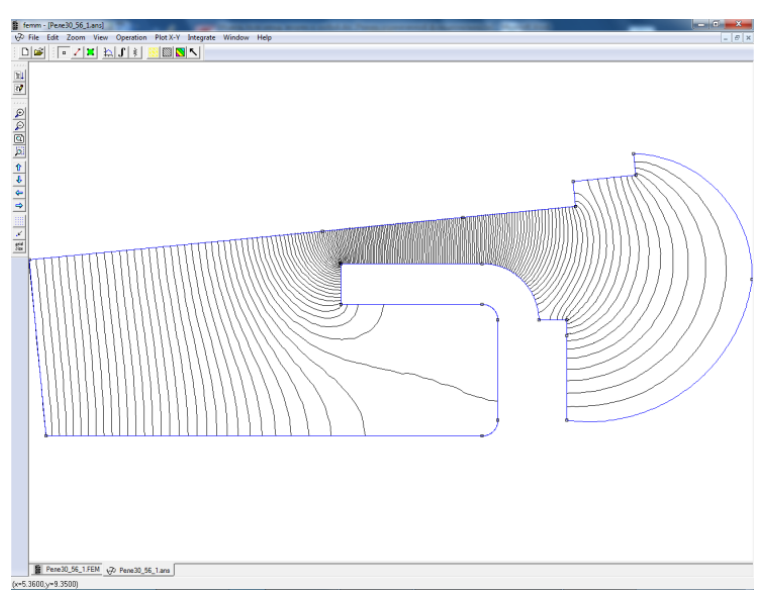

Fig. 4. Distribution of magnetic field in the form of tubes of equal magnetic flux in the area of the working gap and paths of the magnetic flux leakage, built in the FEMM program.

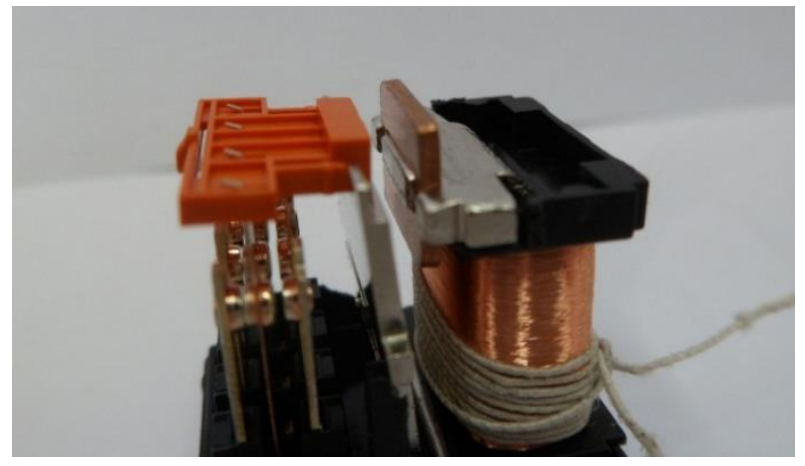

Fig. 5. The Schrack PT570730 series AC 230 V Intermediate relay.

In a relay with variable voltage control, the pole of the magnetic system core is formed by removing the bend, which somewhat reduced the pole area and increased the working gap to $1.7 \mathrm{~mm}$ (Figure 5).

To eliminate armature vibration, a short-circuited copper coil is built into the pole. The design of the working gap zone makes it possible to reduce the 
electrical resistance of the short-circuited loop and increase its efficiency. An increase in the gap will have little effect on the traction characteristics of $\mathrm{AC}$ electromagnet, since the magnetic systems of AC electromagnets are systems with constant flux linkage and, therefore, self-boosting [25].

The kinematic diagrams of intermediate relays with constant voltage control manufactured by Schrack and Finder are shown in Figures 6 and 7.

The kinematic diagrams of the Finder and RP-Ir2 relays are practically the same. The only difference is that the initial working gap for the Finder relay is 0.7 $\mathrm{mm}$, and for the RP-Ir2 relay it is $0.82 \mathrm{~mm}$. The DCcontrolled Schrack relay provides the same switching capacity (nominal switching voltage $240 \mathrm{~V} \mathrm{AC}$, nominal contact current $6 \mathrm{~A}$ ) as the Finder relay (nominal switching voltage $250 \mathrm{~V} \mathrm{AC}$, nominal contact current 7 A). Upon that, for the Schrack relay to operate, it is necessary that its electromagnet ensure the equality of the electromagnetic force to the contact force. In the Finder relay, according to the kinematic diagram, the ratio of the electromagnetic actuation force $\mathrm{P}_{\mathrm{e}_{-} \text {Finder }}$ and the force of contact pressure $\mathrm{P}_{\mathrm{c}_{\_} \text {Finder }}$ is $\mathrm{P}_{\mathrm{c}_{-} \text {Finder }}=\mathrm{P}_{\mathrm{e} \_ \text {Finder }}$ $\times 0.525$. That is, other things being equal, in order to ensure the same switching capacity of the Schrack relay and the Finder relay, the electromagnet in the Finder relay must develop an electromagnetic force almost 1.9 times more than that in the Schrack relay. The power consumption of the Schrack relay with an initial working gap of $1.2 \mathrm{~mm}$ is $0.75 \mathrm{~W}$. At the same time the power consumption of the Finder relay with an initial working gap of $0.7 \mathrm{~mm}$ is $1 \mathrm{~W}$, which is determined by the kinematic diagram.

Thus, the Schrack relay is recommended as a prototype for the development of a new type of Russian relay.

The mechanical characteristics of the electromagnetic drives of the above-considered relays were investigated, they are presented in combined form in Figure 8.

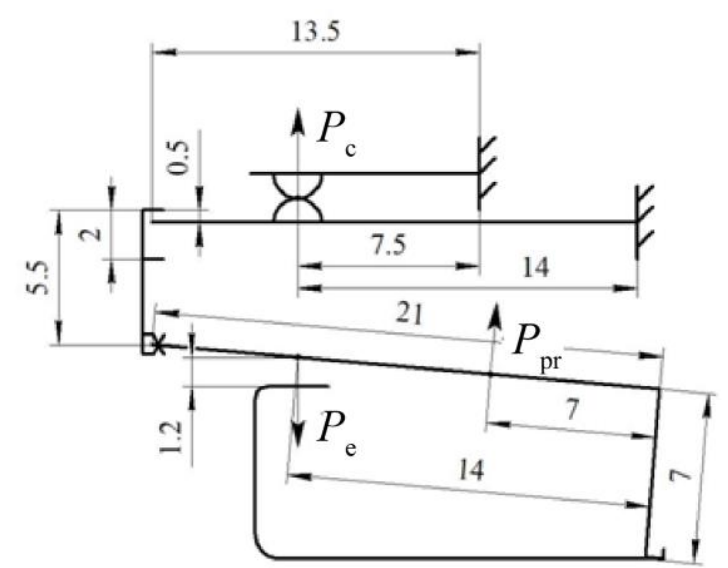

Fig. 6. Kinematic diagram of the Schrack PT570220 series relay of $220 \mathrm{~V}$ DC.

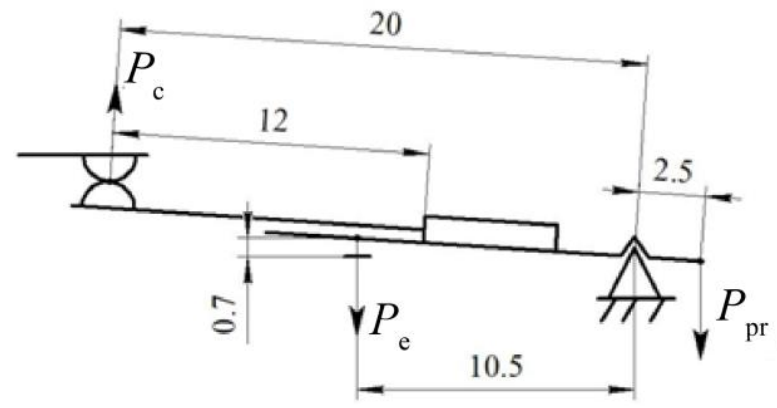

Fig. 7. Kinematic diagram of the Finder series 55.34.9.220.9202 relay of $220 \mathrm{~V}$ DC.

The mechanical characteristics of the 1.4.P.0.0.D.119.0.06.1RP-Ir2 and 55.34.9.220.9202 Finder relays are quite similar due to the similarity of their magnetic systems.

The mechanical characteristic of the Schrack PT570220 DC voltage relay is significantly lower than the characteristics of the 1.4.P.0.0.D.119.0.06.1 RP-Ir2 and 55.34.9.220.9202 Finder relays. Apparently, this affects the difference in magnetomotive forces of actuation to a greater extent and explains the difference in the indicators of vibration and shock resistance of these relays. It should also be noted that the mechanical characteristics of the Schrack relay have free travel of the armature (in Figure 8, the free travel is $0.2 \mathrm{~mm}$ ). It is presumably associated with a decrease in power consumption, an increase in vibration and shock resistance. Free travel is conventionally called the armature stroke without clutching with the contact system using a pusher. That is, during free travel, only a leaf return spring acts on the armature.

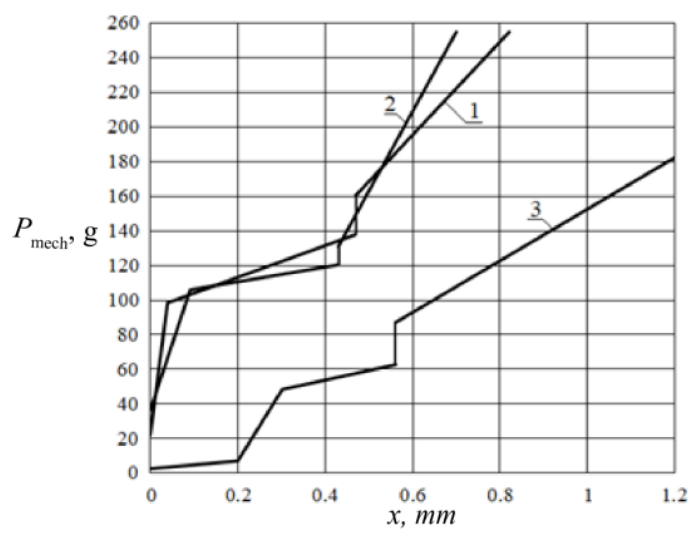

Fig. 8. Mechanical characteristics of electromagnetic drives of intermediate relays: 1 - RP-Ir2 1.4.P.0.0.D.119.0.06.1; 2 Finder 55.34.9.220.9202; 3 - Schrack PT570220.

\section{Conclusions}

1. Movable and fixed contacts of the Schrack relay contact system are mounted on one relay base, which facilitates the technology of their setting and adjustment.

2. The electromagnetic drive of the Schrack relay has a form of a system consisting of two L-shaped movable and fixed parts, with the armature parallel to the core 
axis. It ensures the participation of the leakage magnetic flux in the creation of the electromagnetic moment.

3. The stiffness of the flat return spring of the Schrack relay is $22 \mathrm{~g} / \mathrm{mm}$, the stiffness of coil springs of the Finder and RP-Ir2 relays are $42.9 \mathrm{~g} / \mathrm{mm}$ and 92.09 $\mathrm{g} / \mathrm{mm}$, respectively. So, the spring of the Schrack relay is "softer" as compared to the coil springs of its analogs, which simplifies the process of tuning to the required operation voltage $(0.6 \div 0.65$ of the rated supply voltage).

4. The free travel of the armature of the Schrack relay electromagnet, due to the presence of the pusher, ensures a decrease in power consumption while maintaining the vibration and shock resistance of normally closed contacts at a given level.

5. The fixed contacts are located in the base of the Finder relay and the movable contacts are located on the armature by means of the block attached to. This makes it difficult to calibrate the contact system and set the relay to a given operating voltage.

6. It is proposed to use the Schrack relay as a prototype for the development of a new series relay with a similar type of kinematic circuit and configuration of the magnetic system.

\section{References}

1. N.Yu. Zaitsev, V.N. Petrov, D.S. Sazanov, G.P. Svintsov, Analysis of small intermediate relays of domestic and foreign production // Problems and prospects for the development of energy, electrical engineering and energy efficiency: materials of the III International Scientific and Technical conference. Cheboksary: Chuvash University Publishing House, 404-410 (2019).

2. The Finder Relays Catalog.

3. The Relpol Relays Catalog.

4. The SCHRACK TECHNIK Products Catalog.

5. TU 16-523.593-80 Specifications "Intermediate relay of RP21M and RP21MN series". Amend. 25.

6. TU 16-93 IGFR.647115.069 TU Specifications "Intermediate relay of REP26 series". Amend. 8.

7. The relay REK59 SHRVI.647115.001-48 SHRVI.647115.001 TU 1. Irkutsk Relay Plant. URL:

https://www.irzirk.ru/catalog/zacehlennye/rele_rek5 9_srvi64711500148_srvi647115001_tu_1/(access date: 25.09 .2019 ).

8. The relay REK59 SHRVI.647115.001-57 SHRVI.647115.001 TU 1. Irkutsk Relay Plant. URL:

https://www.irzirk.ru/catalog/zacehlennye/rele_rek5 9_srvi64711500157_srvi647115001_tu_1/(access date: 25.09.2019).

9. The relay RP-Ir2 1.4.P.0.0.D.110.0.00.1 FIMD.640171.001 TU 1. Irkutsk Relay Plant. URL: https://www.irzirk.ru/catalog/zacehlennye/rele_rpir2 _14p00d1100001_fimd640171001_tu_1/(access date: 25.09.2019).
10. Accident prevention circular No. Ts-10-87 (z). On improving the reliability of relay protection devices, automation and technological protection in case of a ground fault in the DC network. - Moscow, 1987.

11. Pat. № 6023212 US. Electromagnetic relay with manual actuator/L. Mader. 2000.

12. Y.I. Gracheva, O.V. Naumov, Evaluation criteria of contact group technical state concerning electrical appliances, International Journal of pharmacy and Technology, 4, 27084-27091 (2016)

13. Evaluation criteria of contact group technical state concerning electrical appliances. - Journal of engineering and applied sciences 11 (special issue 1). p.26763-26770, 2016.

14. D.D. Micu, I.V. Ivshin, E.I. Gracheva, O.V. Naumov, A.N. Gorlov, Influence of resistance of contact units of switching devices on the electric power losses in shop networks of low tension, E3S Web of Conferences, 124, 02013 (2019)

15. D.D. Micu, I.V. Ivshin, E.I. Gracheva, O.V. Naumov, A.N. Gorlov, Influence of value resistance contact units of switching devices on losses of the electric power in shop networks of low tension, IOP Conference Series: Materials Science and Engineering, 643, 2019.

16. E.I. Gracheva, O.V. Naumov, Estimation of Power Losses in Electric Devices of the Electrotechnical Complex. - International Conference on Industrial Engineering, Applications and Manufacturing (ICIEAM) (2019).

17. E.I. Gracheva, O.V. Fedorov, Forecasting Reliability Electrotechnical Complexes of In-Plant Electric Power Supply Taking into Account LowVoltage Electrical Apparatuses, International Conference on Industrial Engineering, Applications and Manufacturing (ICIEAM) (2019).

18. V.M. Maksimov, A.P. Mikhailov. Design of lowcurrent switching elements: teaching aids. Ministry of Education and Science of the Russian Federation, Chuvash State University named after I. N. Ulyanov. Cheboksary: Publishing house of Chuvash University, 171 (2016)

19. V.V. Afanas'ev, Y.M. Zaitsev, O.A. Nikitina et al., Creation of a DC forced armor electromagnet supplied by a circuit with a ballast resistor and minimized with respect to the mass of active materials, Russ. Electr. Engin. 88, 416-419 (2017). https://doi.org/10.3103/S1068371217070033.

20. Y.M. Zaitsev, I.P. Ivanov, O.A. Petrov et al., Minimizing the power consumption of a clappertype dc electromagnet in intermittent operation, Russ. Electr. Engin., 86, 474-478 (2015). https://doi.org/10.3103/S1068371215080131.

21. V.V. Afanas'ev, N.V. Russova, G.P. Svintsov, Static Electromagnetic Characteristics of DirectCurrent Single-Winding Plunger Shell-Core Magnetic Systems with a Flat Cylindrical Pole, Russ. Electr. Engin., 89, 114-117 (2018). https://doi.org/10.3103/S1068371218020025. 
22. N.Y. Zaitsev, V.N. Petrov, G.P. Svintsov et al., Calculation of a Valve Magnetic System of Maximum Current Release of a Circuit Breaker, Russ. Electr. Engin., 89, 459-463 (2018). https://doi.org/10.3103/S1068371218080114.

23. Y.M. Zaitsev, E.N. Kadyshev, V.N. Petrov et al. A Design of a Minimized Shell-Type Plunger Constant-Voltage Electromagnet, Russ. Electr. Engin., 89, 473-476 (2018). https://doi.org/10.3103/S1068371218080138

24. N.Y. Zaitsev, V.M. Maksimov, V.N. Petrov et al. A Valve Magnetic System with Increased Operational Sensitivity of Overcurrent Release, Russ. Electr. Engin., 90, 549-552 (2019). https://doi.org/10.3103/S1068371219080108.

25. E.G. Akimov, G.S. Belkin, A.G. Godzhello, V.G. Degtyar, Fundamentals of the theory of electrical devices, 592 (St. Petersburg: Lan, 2015)

26. M. Raza, A. E. Ahmed, A. S. Alshebami, and A. G. Polyakova, Renewable Energy use and its Effects on Environment and Economic Growth: Evidence from Malaysia, International Journal of Energy Economics and Policy 10 (5), 50-57 (2020). doi:10.32479/ijeep.10219

27. N. Ketoeva, N. Soldatova, and S. Ilyashenko, Lean Manufacturing as a Tool for Increasing Labor Productivity at the Enterprise, E3S Web of conferences $\quad 124, \quad 04015 \quad$ (2019) doi:10.1051/e3sconf/201912404015 